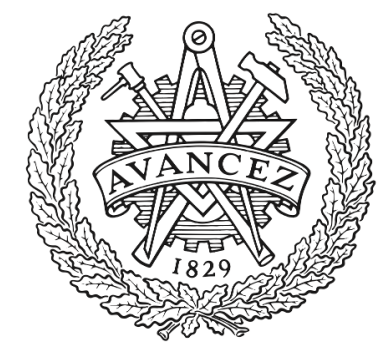

CHALMERS

UNIVERSITY OF TECHNOLOGY

\title{
A High-Gain High-Efficiency Corporate-Fed Slot Array Antenna directly Fed by Ridge Gap Waveguide at 60-GHz
}

Downloaded from: https://research.chalmers.se, 2023-04-26 12:50 UTC

Citation for the original published paper (version of record):

Liu, J., Vosoogh, A., Uz Zaman, A. et al (2017). A High-Gain High-Efficiency Corporate-Fed Slot Array Antenna directly Fed by Ridge Gap

Waveguide at 60-GHz. 2017 International Symposium on Antennas and Propagation (ISAP). http://dx.doi.org/10.1109/ISANP.2017.8229041

N.B. When citing this work, cite the original published paper. 


\title{
A High-Gain High-Efficiency Corporate-Fed Slot Array Antenna directly Fed by Ridge Gap Waveguide at $60-\mathrm{GHz}$
}

\author{
Jinlin Liu, Abbas Vosoogh, Ashraf Uz Zaman, and Jian Yang \\ Department of Electrical Engineering, Chalmers University of Technology, Gothenburg, Sweden \\ Jinlin.Liu@chalmers.se
}

\begin{abstract}
An $8 \times 8$ slot array with high-efficiency and corporate-fed single layer by ridge gap waveguide at $60-\mathrm{GHz}$ is introduced in this paper. The manufactured antenna depicts more than $19.6 \%$ bandwidth with input reflection coefficient better than $-10 \mathrm{~dB}$ and the aperture efficiency higher than $70 \%$ with around $26 \mathrm{dBi}$ realized gain between 58 and $66 \mathrm{GHz}$.
\end{abstract}

Index Terms-Artificial Magnetic Conductor (AMC), ridge gap waveguide, high efficiency, single layer, millimeter wave and slot array antenna.

\section{INTRODUCTION}

Currently, the unlicensed 60-GHz frequency band has been paid lots of attention for high-speed wireless communications. For point-to-point wireless systems at $60 \mathrm{GHz}$, antennas with high-gain and wideband are required. Compared with the conventional antenna technologies in wireless links, such as reflectors, horns and lens antennas, planar array antennas have a huge advantage in millimeter waves $(\mathrm{mmWs})$ because its light weight and small volume. In [1] a wideband and high efficiency corporate-fed slot array antenna based on hollow waveguide in the $60-\mathrm{GHz}$ band is reported. It realizes $13.8 \%$ bandwidth with reflection less than $-10 \mathrm{~dB}$ and 32 $\mathrm{dBi}$ gain in the $60-\mathrm{GHz}$ band. However, its manufacturing is complicated and the fabrication cost is therefore expensive. The newly introduced gap waveguide technology [2] is a proper alternative to conventional hollow waveguide because it does not need good electrical contact between antenna components. Antennas with wideband, high gain, high efficiency characteristics at $60-\mathrm{GHz}$ based on gap waveguide have been introduced [3]-[6]. All those mentioned antennas have backed-cavity layer in the middle to provide enough space for corporate-feeding network to increase the bandwidth of the antennas. On the other hand, series-fed antenna array can avoid this middle backed-cavity layer and consequently the manufacture cost is much decreased [7]-[8]. However, its bandwidth is much narrower compared to multilayer corporate distribution networks. In this paper, we will initially introduce an $8 \times 8$ high-efficiency corporate-fed single layer slot array antenna at $60-\mathrm{GHz}$. The proposed antenna is based on ridge gap waveguide technology. It merely consists of feed network layer and slot layers. Both separate layers are fabricated by Computerized Numerical Control (CNC) milling technology.

\section{ANTENNA CONFIGURATION}

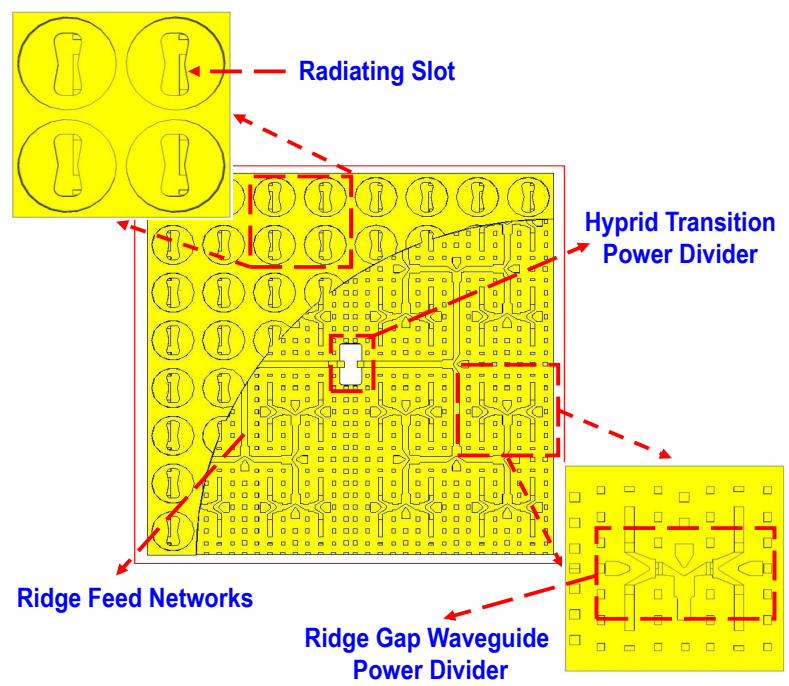

Fig. 1. Detailed 3-D view of single-layer slot array unit cell.

The demonstration of the proposed slot array antenna is illustrated in Fig. 1. The whole structure consists of $4 \times 4$ subarrays, which has an effective area of $8.4 \times 8.4 \mathrm{~mm}^{2}$. At the bottom layer a ridge gap waveguide corporate network feeds all sub-arrays with identical phases and amplitudes. The radius of the round radiating slots is $1.85 \mathrm{~mm}$ and the distances between every two slots in both lateral and vertical directions

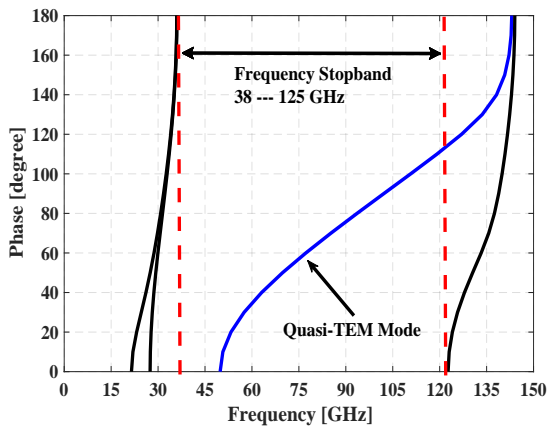

Fig. 2. Dispersion diagram of ridge gap waveguide structure in this paper. 

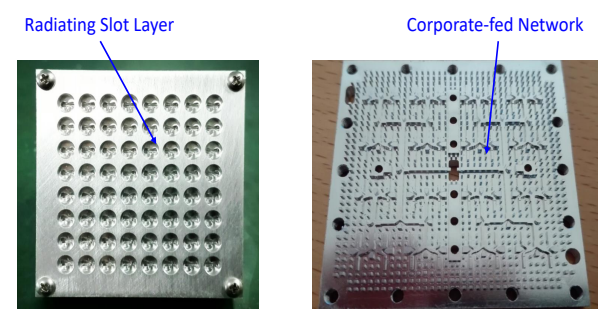

Fig. 3. Picture of the proposed $8 \times 8$ alot array antenna.

are $4.2 \mathrm{~mm}$. The corresponding dimensions of metallic pin are very well selected to create a stopband which totally covers the target. The dispersion diagram of a metallic pin is depicted in Fig. 2.

\section{SIMULATED AND MEASURED RESULTS}

The manufactured slot array antenna is shown in Fig. 3. Fig. 4 (a) and (b) depict the simulated radiation patterns both in E- and H-planes at 57, 61 and $66 \mathrm{GHz}$. The measured input reflection coefficients as well as the simulated and measured gain are all illustrated in Fig. 5. The measured reflection coefficient is below $-10 \mathrm{~dB}$ from $56 \mathrm{GHz}$ to $67 \mathrm{GHz}$. The measured total aperture efficiency of the proposed antenna is high than $70 \%$ between $58 \mathrm{GHz}$ and $66 \mathrm{GHz}$.

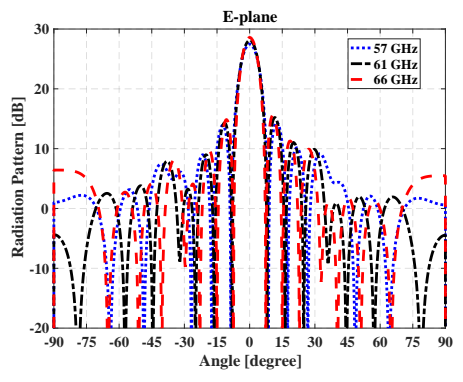

(a)

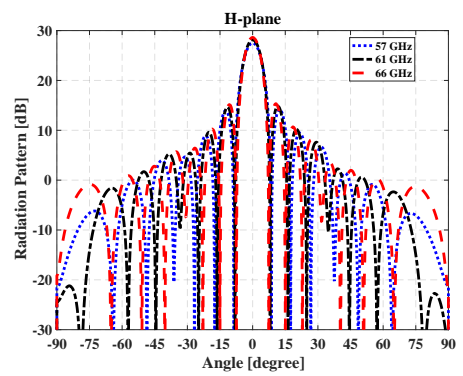

(b)

Fig. 4. (a) Simulated radiation pattern of present antenna in E-plane. (b) Simulated radiation pattern of present antenna in H-plane.

\section{CONCLUSION}

In this work we have introduced a corporate-fed single layer $8 \times 8$ slot array antenna with high gain and high efficiency characteristics based on ridge gap waveguide at $60-\mathrm{GHz}$. The present antenna has merely the feed network layer and the radiating slot layer so that the fabrication cost will be reduced.

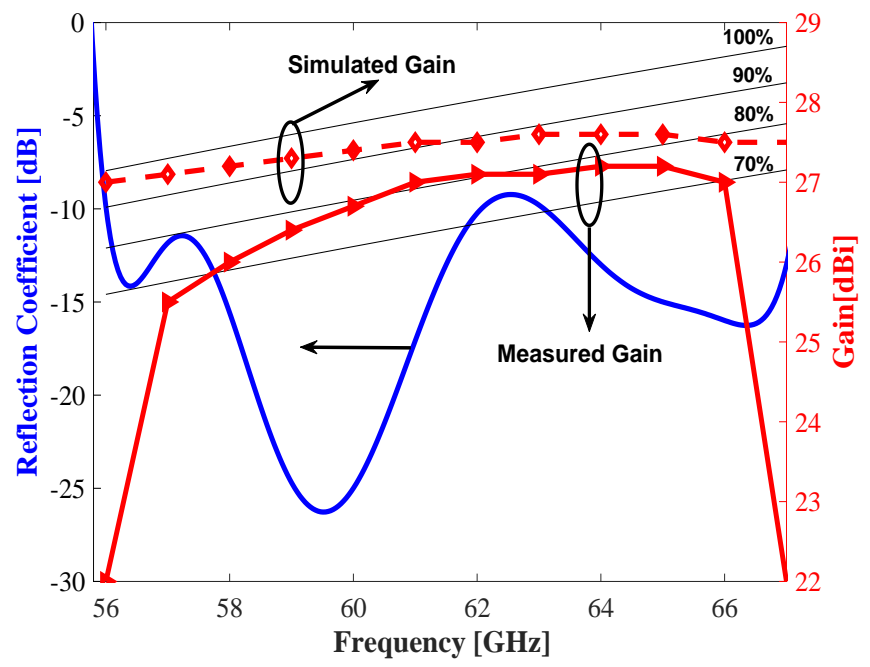

Fig. 5. The measured reflection coefficients and the simulated and measured gain of proposed $8 \times 8$ slot array antenna based on ridge gap waveguide.

\section{REFERENCES}

[1] Y. Miura, J. Hirokawa, M. Ando, Y. Shibuya and G. Yoshida, "Doublelayer full-corporate-feed hollow-waveguide slot array antenna in the 60 GHz band, "IEEE Trans. Antennas Propag., vol. 59, no. 8, pp. 2844 2851, Aug. 2011

[2] P.-S. Kildal, "Three metamaterial-based gap waveguides between parallel metal plates for $\mathrm{mm} / \mathrm{submm}$ waves, " in 3rd European Conference on Antennas and Propagation, EuCAP 2009, pp. 28-32.

[3] D. Zarifi, A. Farahbaksh, A. Uz Zaman and P.-S. Kildal, "Design and fabrication of a wideband high-gain $60-\mathrm{GHz}$ corrugated slot antenna array with ridge gap waveguide distribution layer, "IEEE Transactions on Antennas and Propagation, vol. 65, no. 4, pp. 2117-2122, April 2017.

[4] J. L. Liu, A. Vosoogh, A. U. Zaman and J. Yang, "Design and Fabrication of a High Gain 60-GHz Cavity-backed Slot Antenna Array fed by Inverted Microstrip Gap Waveguide, "IEEE Trans. Antennas Propag., vol. 65, issue: 4, April, 2017

[5] A. Vosoogh, P.-S. Kildal and Vessen Vassilev, "Wideband and High-Gain Corporate-Fed Gap Waveguide Slot Array Antenna with ETSI Class II Radiation Pattern in V-Band, "IEEE Trans. Antennas Propag., vol. 65, issue: 4, April, 2017.

[6] J. L. Liu, A. Vosoogh, A. Uz Zaman and P.-S. Kildal, "Design of $8 \times 8$ slot array antenna based on Inverted Microstrip Gap Waveguide, "Antennas and Propagation (ISAP), 2016 International Symposium on, 24-28, October, 2016.

[7] S. Park, Y. Tsunemitsu, J. Hirokawa and M. Ando, "Center Feed Single Layer Slotted Waveguide Array, "IEEE Trans. Antennas Propag., vol. 54, issue: 5, May, 2006.

[8] M. Ando, J. Hirokawa, T. Yamamoto, A. Akiyama, Y. Kimura and N. Goto, "Novel Single-Layer Waveguides for High-Efficiency MillimeterWave Arrays "IEEE Transactions on Microwave Theory and Techniques, vol. 46, issue: 6, June, 1998. 